\title{
ЗНАЧЕНИЕ МЕЖДУНАРОДНОГО РЫНКА ИНТЕЛЛЕКТУАЛЬНОЙ СОБСТВЕННОСТИ В МИРОВОЙ ЭКОНОМИКЕ
}

\author{
(c) 2019 Михайлов Максим Викторович \\ аспирант кафедры мировой экономики \\ РЭУ им. Г.В. Плеханова, Россия, Москва \\ Начальник юридического отдела ООО «Союзпатент» (sojuzpatent.com), Россия, Москва \\ E-mail: maxim.v.mikhailov@gmail.com \\ ORCID0000-0002-2905-8199 \\ (c) 2019 Зубенко Вячеслав Васильевич \\ доктор экономических наук, профессор, \\ профессор Департамента Мировой экономики и Мировых финансов \\ Финансовый Университет при Правительстве Российской Федерации, Россия, Москва \\ E-mail:VVZubenko@fa.ru \\ ORCID0000-0003-1444-3884
}

В 21 веке качественное и количественное значение интеллектуальной собственности мировой экономики ежегодно растет. В статье рассматривается роль и место международного рынка интеллектуальной собственности для глобального рынка, а также влияние ключевых стран мира, включая Россию, в международном обмене технологиями.

Ключевые слова: рынок интеллектуальной собственности, технологический платежный баланс, нематериальные активы, интеллектуальный капитал

Международный рынок интеллектуальной собственности предлагается исследовать, главным образом, как совокупность трансграничных сделок, основанных на передаче объектов интеллектуальной собственности. Его формальное отличие от «традиционного рынка товаров» заключается, прежде всего в том, что система бизнес отношений строится вокруг «продукта», существующего в «единственном первоначальном экземпляре». А другие отличия являются порождением данной специфики. Это во многом объясняет тот факт, что на этом рынке отсутствует общее пространство с едиными правилами торговли, типовыми продуктами и сделками. Также нет торговой площадки, общей инфраструктуры и единой методологии ценообразования. Не исключено, что в обозримом будущем здесь произойдут существенные трансформации.

В тоже время, активно работают мировые рынки материальных ценностей, не имеющие национальной привязки. Абстрактно, они предлагают огромный набор товаров, связанных с большим количеством изначальных рынков, начиная от энергетических ресурсов, до рабочей силы. При этом правовое регулирование и охрана интеллектуальной собственности, порожденная конкретной сферой производства и логи- стикой, связана с определенным государством. Руководствуясь многоуровневой системой приоритетов, оно создает конкретный механизм защиты.

Хотя основные международные акторы-регистраторы интеллектуальной собственности, неизменно декларируют поддержку практике унификации режимов её регулирования на мировом рынке, но ни одна из ведущих стран не отказывается от системы «национального приоритета» в пользу «наднациональных принципов». Авторитет и инструментарий методологии и практики использования в этой связи «национального режима» и «режима наибольшего благоприятствования» определяется, зачастую, степенью подготовленности соперничающих групп юристов и экспертов, участвующих в арбитражных или судебных заседаниях.

Наличие различных законодательных баз, а также традиций, связанных с условиями реализации принятых решений, породили огромное пространство, на котором, в условиях различных национальных юрисдикций, настойчиво взаимодействуют партнёры. Писанные и неписанные законы, регламенты и практики являются основой для активности центростремительных и центробежных сил. Такой подход надо 
учитывать, как при рассмотрении развития общих тенденций, так и интересов юридических игроков.

Параметры международного рынка интеллектуальной собственности чрезвычайно обширны. Набор инструментов и организационные факторы, используемые в процессе сделки между контрагентами, также чрезвычайно многообразны. Из их обилия, прежде всего, надо выделить ключевые элементы, благодаря которым категория «международный рынок интеллектуальной собственности» может быть исследована в динамике. В качестве системообразующей основы, в процессе анализа следует сделать акцент, прежде всего, на взаимосвязи явлений, что выражают такие дефиниции, как «интеллектуальная собственность», «нематериальные активы», «интеллектуальный капитал».

Сопоставительный перечень основных объектов интеллектуальной собственности (в качестве собирательного понятия), зафиксирован в Конвенции ВОИС (1967 г.). Он - свидетельство того непреложного факта, что, любое из них реально существует лишь в случае формальной регистрации временного исключительного права (включая личные неимущественные права авторов) на результаты такой деятельности, либо в качестве средства индивидуализации. При этом охрана интересов правообладателя несколько отличается от принципов защиты интересов патентообладателя и изобретателя.

Дефиниция «интеллектуальная собственность» созвучна понятию «нематериальные активы». В системе бухгалтерского учета под последними понимаются немонетарные или внеоборотные активы долгосрочного использования. Как известно, они не имеют физическое выражение, но при этом обладают стоимостной оценкой и могут приносить доход. В этом случае, согласные юридическим нормам подавляющего большинства стран, а также российским стандартам бухгалтерского учета, «нематериальные активы» идентичны по своей сути - «интеллектуальной собственности», при условии, если это не противоречит национальному законодательству.

Феномен «интеллектуальной собственности» известен многие столетия. Со времени возникновения капитализма она (наряду с финансовым капиталом) служила одним из важных элементов развития предприятия. В индустриальном обществе, это определяющий элемент формирования материальной основы общества.
Постиндустриальная экономика, основанная на знаниях - главный источник динамичного развития и генерирования знаний. Таким образом, «интеллектуальный капитал» сегодня стал основой для вызревания нового мирохозяйственного качества, которое на новом технологическом уровне, создает цепочку информационного общества.

Фактически, «интеллектуальный капитал» является широкой основой, объединяющей в едином бизнес-процессе и интеллектуальную собственность, и деловую репутацию компании (с её нематериальными активами), а также рыночные инфраструктурные активы. Но, прежде всего, человеческий капитал. При этом, структура «интеллектуального капитала», помимо «интеллектуальной собственности», включает в себя пестрый набор элементов, которые не могут быть реализованы самостоятельно. Прежде всего, так как не имеют стоимостной оценки. Их приблизительная цена может быть определена эмпирическим путем, в процессе публичной реализации предприятия.

Анализ рынка интеллектуальной собственности касается, прежде всего, оборота исключительных прав на юридически охраняемые результаты интеллектуальной деятельности (объекты интеллектуальной собственности). По данным ВОИС, доля интеллектуальной собственности в стоимость всех проданных товаров в период 2000-2014 гг. в среднем составляла 30,4\% (например, в смартфоне Apple она составляет 42\%) [8]. При этом, по данным Всемирного банка, объем платежей за использование объектов интеллектуальной собственности с 2000 по 2017 г. вырос в 5,17 раза (рис. 1).

С целью завоевания и утверждения на региональных и международных рынках и технологий компании ведут жесткую борьбу. Прежде всего, в сфере охраны корпоративной интеллектуальной собственности. Ежегодный рост количества международных заявок на регистрацию объектов интеллектуальной собственности говорит о возрастающем значении результатов интеллектуальной деятельности для бизнеса и мировой экономики в целом. Так, с 2009 по 2017 гг. ежегодное количество подаваемых международных патентных заявок на изобретения выросло с 1855900 до 3168900, а количество заявок регистрацию товарного знака по международной мадридской системе за этот же период выросло с 5207400 до 12387600 [5]. 


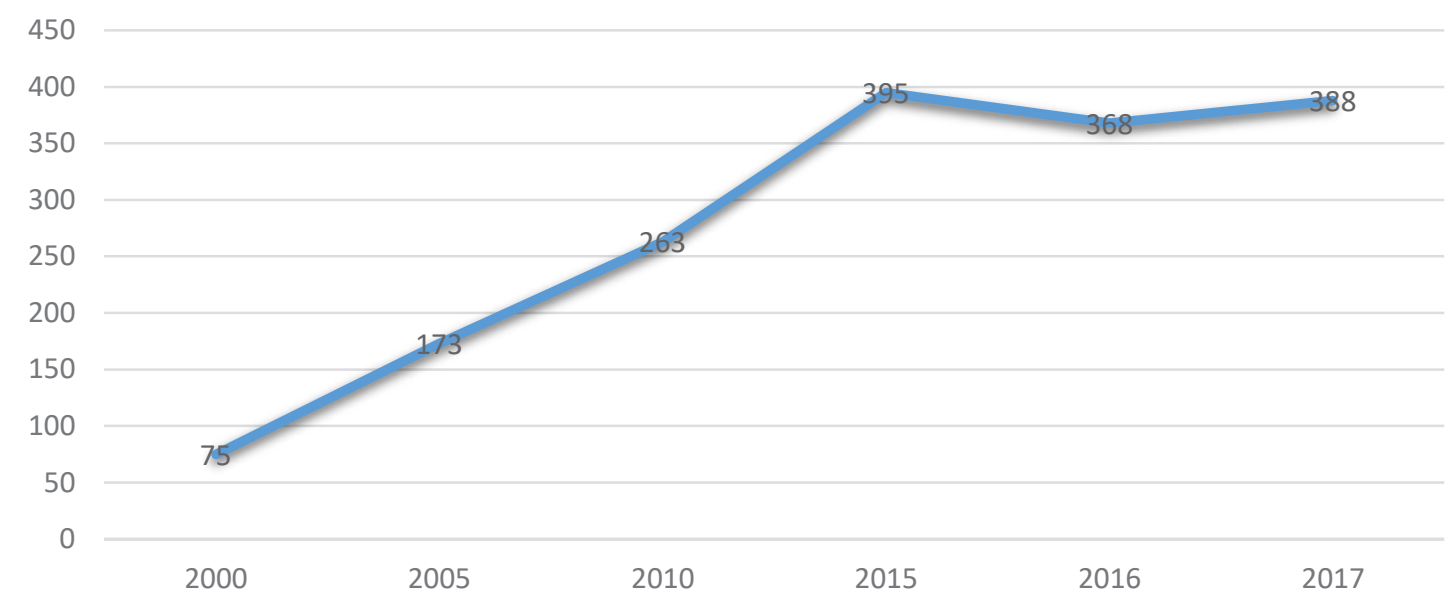

Puc. 1. Объем платежей за использование объектов ИС, всего в мире, в млрд. долл. Источник: составлено автором по данным с сайта Всемирного банка [4]

В решающей степени это связано с особенностями функционирования отраслей обрабатывающей промышленности. По мнению член-корреспондента РАН Спартака А.Н. «при современной экспортной квоте в валовом продукте мировой обрабатывающей промышленности на уровне 90\% и доле обработанных промышленных изделий в глобальном товарном экспорте в размере 73\% можно утверждать, что значительная часть международно торгуемой стоимости сформирована различного рода интеллектуальными ресурсами. Тем более, - особо подчеркивает исследователь, - во многих секторах торговли услугами работает практически чистый интеллект (торговля интеллектуальной собственностью, услугами в области НИОКР, инжиниринговыми, компьютерными, консалтинговыми, управленческими услугами, услугами в сфере культуры и креативных индустрий, др.)» [3, С. 8-9]. При этом, особое внимание нужно об- ратить на динамику доходов от использования нематериальных активов в обрабатывающих отраслях, которые за период 2000-2014 гг. выросли на три четверти [8].

$\mathrm{B} \mathrm{XX}$ веке производственная цепочка в основном сводилась к трансформации сырья в запчасти и компоненты, из которых затем изготавливалась конечная продукция. Стадий производства было относительно немного. Они располагались в одном географическом районе, а иногда и под одной крышей.

Что касается производства в XXI веке, то его часто изображают с помощью «улыбающейся» кривой, впервые предложенной Стэном Ши, основателем Acer, приблизительно в 1992 г. По его наблюдению, оба конца цепочки создания ценности дают бо́льшую добавленную стоимость, чем средняя ее часть, что приводит к более широкой «улыбке» с течением времени. Как показано на рис. 2, «улыбающаяся» кривая свидетель-

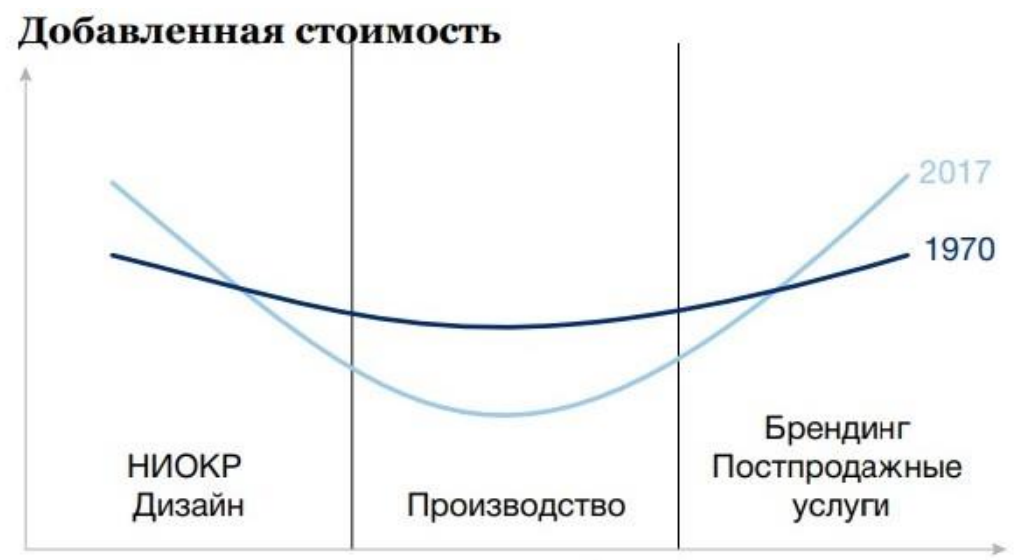

Стадия производства

Puc. 2. Кривая Стэна Ши в 1970 и 2017 гг.

Источник: Доклад ВОИС «О состоянии интеллектуальной собственности в мировой экономике 2017 г.» [1] 
ствует о росте значимости допроизводственных и постпроизводственных этапов, а также о том, что именно на этих стадиях создается все большая доля общей стоимости продукции.

Концепция «улыбающейся» кривой отражает усиление в мировой экономике роли нематериальных активов, а именно НИОКР, технологий, дизайна и брендинга, а также навыков работников и управленческих ноу-хау. Хозяйствующие субъекты постоянно работают над увеличением нематериального капитала, так как это позволяет им обходить конкурентов.

Согласно данным ОЭСР, основными нетто-лидерами мирового рынка знаний (по величине положительного сальдо технологического платежного баланса страны) на протяжении более десяти лет являются (на начало 2016 г.) США (41,9 млрд. долл.), Япония (27,7 млрд. долл.), Великобритания (19,8 млрд. долл., ФРГ (18,1 млрд. долл.), Швеция (12,2 млрд. долл.).

Анализ нетто-сальдо технологического платёжного баланса стран представленных на рис. 3 показывает относительно пологий рост. Исключение составляют два кризисных периода мировой экономики в 2008-2009 гг. и 2014-2015 гг. Очевидно, что данная ситуация отражает общую мирохозяйственную тенденцию - наращивание технологического потенциала. Она связана, по крайней мере, с двумя обстоятельствами. Прежде всего, нужно отметить тенденцию растущего эффекта использования технологической базой, как следствие развития микроэкономической адаптации предприятий. Другим фактором выступает процесс технологической глобализации. Результаты объективного процесса интернационализации инноваций проявляются в ужесточении степени конкуренции ТНК на мировых рынках. Которые, собственно, и являются основными бизнес - партнерами на мировом рынке технологий.

Данную тенденцию отражает тот непреложный факт, что такого рода технологические лидеры мира, как - Республика Корея и Швейцарская Конфедерация - имеют устойчивое отрицательное сальдо. При этом, государства входят в число крупнейших инвесторов в сфере НИОКР. Этот факт отражает сложившуюся в мировых отношениях практику, когда, относительно небольшое число признанных экономических лидеров не в состоянии позволить себе содержать научно-техническую базу, аналогичную той, что существует в таких инновационных гигантах, как Соединенные Штаты, Китай, Израиль, Германия, Франция и т.д.

В ряде государств, прежде всего в Новых индустриальных странах, упор делается на закупках «ординарных технологий». Они являются основой организации массового производства, которое служит основным источником экономического роста и социального развития этих стран. Кстати, нечто напоминающее отмеченный процесс пережила, в своей послевоенной

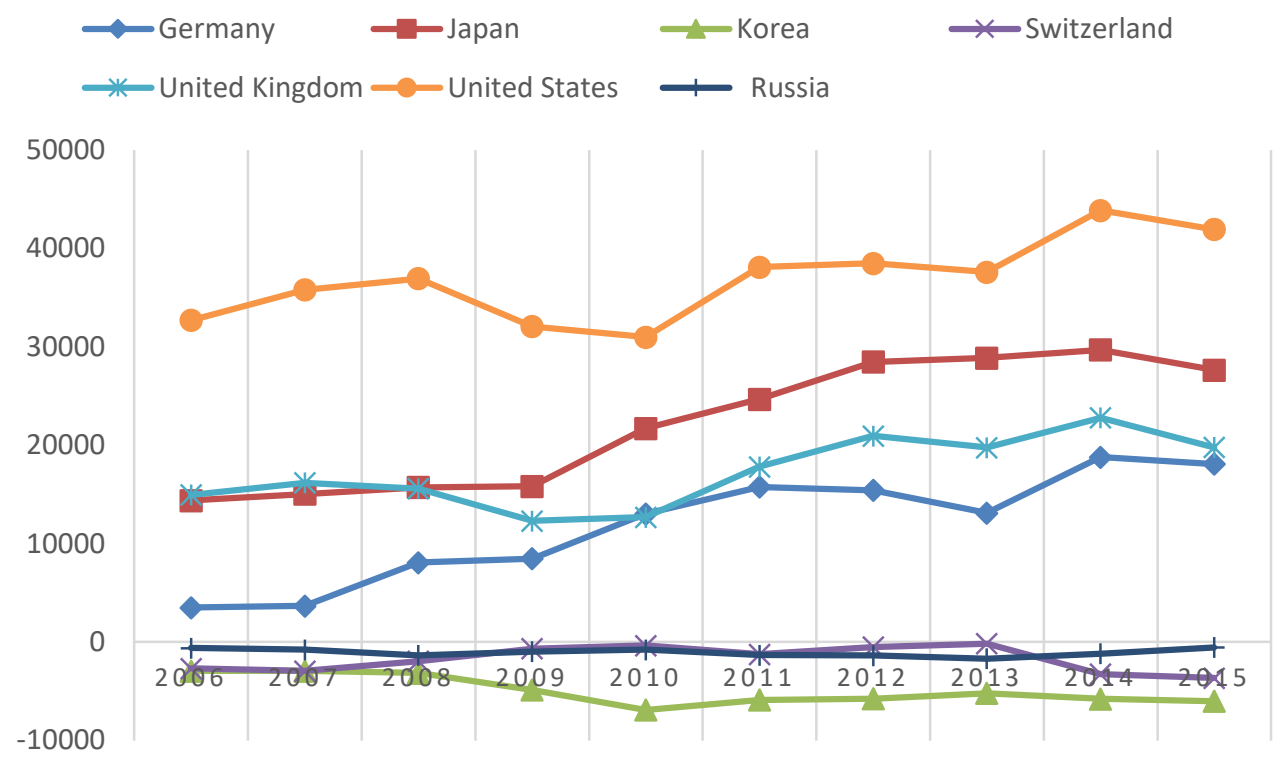

Puc. 3. Основные экспортёры технологий (на базе показателя сальдо технологического платежного баланса ОЭСР) в 2006-2015 гг., млн. долл. Источник: составлено автором на основе данных ОЭСР [6]. 
истории Япония. Когда индустриальные объединения дзайбацу постепенно уступали место новому организационную типу инновационных предприятий.

На нынешнем этапе глобализирующегося мира, такого рода «догоняющие» или «арьергардные» технологии лежат в организации массового производства на предприятиях, порожденных завершающим свой цикл технологическим укладом. Длительное время Россия также относится к этой группе стран. Она является чистым импортером технологий. Причем, отрицательное сальдо технологического платежного баланса имеет тенденцию к его дальнейшему увеличению (рис. 4).

В целом, если сопоставлять показатели внешней торговли большой группы государств, то, в обмене технологическими услугами, прежде всего, отмечается рост квоты роялти и лицензионных выплат. Это дает основание утверждать об интенсификации торговли объектами интеллектуальной собственности, или, по крайней мере, о росте объема их стоимости. При этом, особую активность, как среди экспортеров, так и импортеров, проявляют развитые страны [6]. Хотя среди них, как было отмечено, также проявляется специализация и деление на экспортеров/импортеров специализирующихся на «авангардных» и «арьергардных» технологиях.

При этом важно подчеркнуть, что достоверной, «прозрачной» статистики и информации в этой сфере не существует. Причем, дело не только в конфиденциальности реализуемых бизнес сделок. Их основные параметры, со временем, становятся доступны широкой общественности.
Главная причина феномена «коммерческой тайны» порождена политикой ТНК, максимизация прибыли которых основана на практике «трансфертных цен».

Внутрикорпоративная торговля, всякого рода компонентами и товарами незавершенного производства (что предполагает в дальнейшем создание компанией на их основе конечного товара), осуществляется по внутрифирменным, отличным от рыночного уровня, ценам. Филиальная сеть предприятий, которые собственно и образуют опорные транснациональные предприятия по всему миру, выстраиваются с ориентацией на «технологический разрыв» производства, когда компоненты и полуфабрикаты единого товара производятся его внутрифирменными подразделениями по всему миру.

Делается это с целью минимизации расходов, связанных с процессом производства, когда скрупулезно «взвешиваются» возможности каждой страны-реципиента ТНК: стоимость рабочей силы, наличие необходимой инфраструктуры, расходы по охране окружающей среды, инвестиционный климат, особенности системы налогообложения и т.д. Согласно экспертной оценке, основная доля сделок по передаче технологий (более 60\%) осуществляется между материнскими компаниями ТНК и их филиалами [2, С. 32].

Подводя предварительные итоги о роли и месте международного рынка интеллектуальной собственности в мировой экономике можно сделать вывод что сложившееся здесь положение отвечает интересам развитых стран, и особенно ТНК. Данная ситуация критически вос-

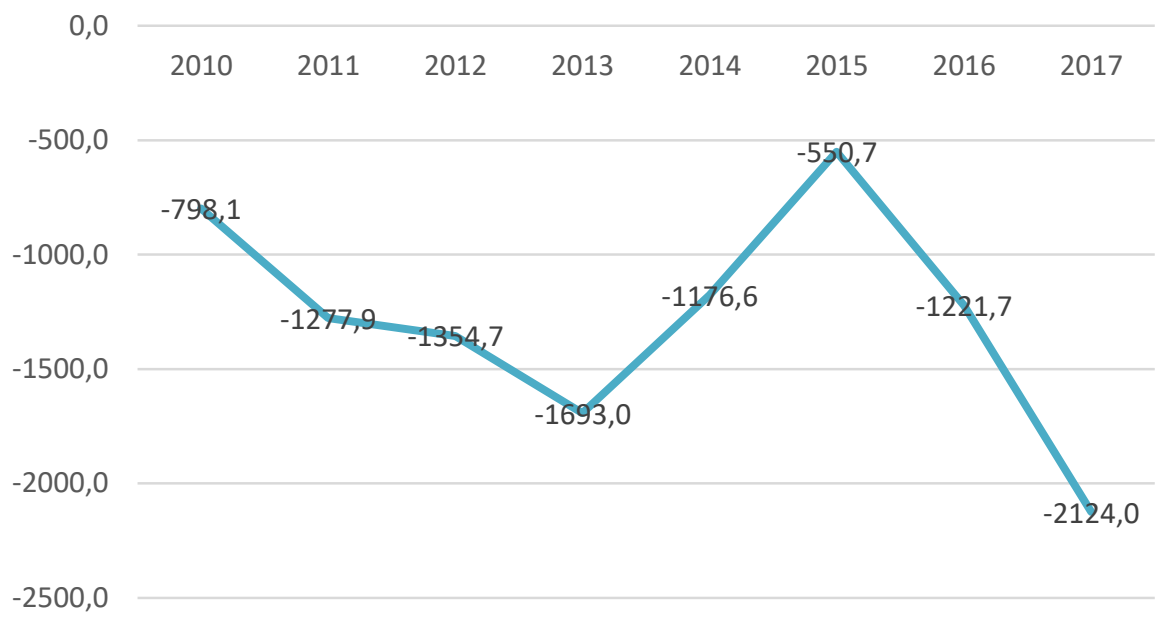

Puc. 4. Сальдо технологического платежного баланса России в 2010-2017 гг., млн. долл. Источник: составлено автором основе данных Росстата [7]. 
принимается развивающимися странами, для которых ограничен доступ к инновациям в силу объективно скромных бюджетов на НИОКР. Одним из главных направлений решения такого рода противоречий является поиск баланса ин- тересов между правообладателями и пользователями ИС, что связано, в том числе, с работой в области антимонопольного регулирования и поиском адекватного современному этапу мирохозяйственных связей характера отношений.

\section{Библиографический список}

1. Доклад ВОИС «О состоянии интеллектуальной собственности в мировой экономике 2017 г.» / URL: https:// www.wipo.int/publications/en/details.jsp?id=4225\&plang=RU (дата обращения 12.09.2019)

2. Лихачев В.А. Международный трансфер технологий: основные тенденции и позиции России // Российский внешнеэкономический вестник. - 2017. № 10.- С. 29-43.

3. Спартак А.Н. Интеллектуализация международной торговли. // Российский внешнеэкономический вестник. - 2018. - № 4. - С. 7-24.

4. Статистический раздел официального сайта Всемирного банка / URL: https://data.worldbank.org/topic/ science-and-technology (дата обращения 12.09.2019)

5. Статистический раздел официального сайта ВОИС / URL: https://www3.wipo.int/ipstats/ (дата обращения 12.09.2019)

6. Статистический раздел официального сайта ОЭСР / URL: https:/www.oecd-ilibrary.org/science-andtechnology/main-science-and-technology-indicators/volume-2018/issue-1_msti-v2018-1-еn (дата обращения 12.09.2019)

7. Статистический раздел официального сайта Росстата / URL: https://www.fedstat.ru/organizations/?expandId =1292993\#fpsr1292993 (дата обращения 12.09.2019)

8. World Intellectual Property Report 2017: Intangible Capital in Global Value Chains» (WIPR2017) / URL: https:// www.wipo.int/pressroom/en/articles/2017/article_0012.html (дата обращения 12.09.2019) 